\title{
Controle de biótipos resistentes de Conyza bonariensis com glyphosate + clorimuron-etílico em função do estádio de desenvolvimento ${ }^{1}$
}

\section{Control of Conyza bonariensis resistant biotypes with glyphosate + chlorimuron- ethyl as a function of development stage}

Fernanda Nunes Bressanin²; Nelson Jayme Neto²; Juliano Francisco Martins³; José Valcir Fidelis Martins ${ }^{4}$; Pedro Luis da Costa Aguiar Alves ${ }^{5}$

Resumo - A dessecação é considerada o manejo inicial das lavouras e uma das práticas mais importantes para implantação da cultura da soja no sistema de plantio direto. Com o cultivo de soja transgênica, a utilização de glyphosate aumentou acentuadamente e proporcionou a seleção de Conyza bonariensis resistente a esse herbicida. Assim, este trabalho teve como objetivo avaliar a eficácia do glyphosate em associação com clorimuron-etílico no controle $C$. bonariensis resistente ao glyphosate, em estágios crescentes de desenvolvimento. Os oito tratamentos foram constituídos pelo uso associado de 2,5 $\mathrm{L} \mathrm{ha}^{-1}$ de glyphosate $\left(1250 \mathrm{~g}\right.$ e.a. ha $\left.{ }^{-1}\right)$ e $60 \mathrm{~g} \mathrm{ha}^{-1}\left(15 \mathrm{~g}\right.$ i.a. ha $\left.{ }^{-1}\right)$ de clorimuron-etílico em plantas com 3 folhas, 4 a 6 folhas, 6 a 9 folhas, 10 a 13 folhas, 13 a 16 folhas, 20 folhas, em florescimento e uma testemunha sem aplicação. $\mathrm{O}$ delineamento utilizado foi o inteiramente casualizado, com seis repetições. Avaliações visuais de controle foram efetuadas aos 7, 15 e 21 dias após a aplicação (DAA), onde também determinou-se a massa seca da parte aérea das plantas. Obteve-se excelentes níveis de controle de $C$. bonariensis resistente ao glyphosate utilizando a associação de glyphosate + clorimuron-etílico em plantas com até 9 folhas.

Palavras-chaves: buva, fenologia, mistura em tanque, eficácia

Abstract - Desiccation is considered the initial crops management and one of the most important practices for soybean deployment in no-tillage system. After starting the cultivation of transgenic soybean, the use of glyphosate in this crop increased expressively and provided Conyza bonariensis selection resistant to this herbicide. This study aimed to evaluate the efficacy of glyphosate in association with chlorimuron-ethyl in controlling glyphosate-resistant $C$. bonariensis, at different growth development stages. Eight treatments were constituted by the associated use of $2.5 \mathrm{~L} \mathrm{ha}^{-1}$ of glyphosate $\left(1250 \mathrm{~g}\right.$ a.e.ha- $\left.{ }^{-1}\right)$ and $60 \mathrm{~g} \mathrm{ha}^{-1}\left(15 \mathrm{~g}\right.$ a.i. ha $\left.{ }^{-1}\right)$ of chlorimuron - ethyl in plants with 3 leaves, 4 to 6 leaves, 6 to 9 leaves, 10 to 13 leaves, 13 to 16 leaves, 20 leaves, in flowering stage and a control without application. Experimental design was a randomized block with six replications. Visual control evaluations were performed at 7, 15 and 21 days after application

\footnotetext{
${ }^{1}$ Recebido para publicação em 18/04/2013 e aceito em 04/06/2014.

${ }^{2}$ Mestrando do Programa de Pós-graduação em Produção Vegetal da Faculdade de Ciências Agrárias e Veterinárias da Universidade Estadual Paulista, <fnunes.agro@yahoo.com.br>, <netojayme@ @otmail.com>.

${ }^{3}$ Engenheiro Agrônomo, Departamento de Biologia Aplicada à Agropecuária da Faculdade de Ciências Agrárias e Veterinárias da Universidade Estadual Paulista <juliano.agro@yahoo.com.br>.

${ }^{4}$ Auxiliar Agropecuário do Departamento de Biologia Aplicada à Agropecuária da Faculdade de Ciências Agrárias e Veterinárias da Universidade Estadual Paulista <martins@ @ fcav.unesp.br>.

${ }^{5}$ Professor Doutor do Departamento de Biologia Aplicada à Agropecuária da Faculdade de Ciências Agrárias e Veterinárias da Universidade Estadual Paulista, <plalves@fcav.unesp.br>.
} 
(DAA), also determining leaves dry mass. Excellent control was found by using the association of glyphosate + chlorimuron-ethyl at plants $\leq 9$ leaves.

Keywords: hairy fleabane, phenology, tank mixture, effectiveness

Há inúmeras dificuldades encontradas pelos produtores que limitam a produção da soja e de outras culturas. Segundo Lorenzi (2008), as plantas daninhas merecem destaque por serem vegetais que crescem onde não são desejadas e se caracterizam pela grande agressividade competitiva. Para o controle dessas plantas indesejáveis, o método o químico com herbicidas para o controle de buva (Conyza bonariensis) na dessecação pré-semeadura da soja, tem sido frequentemente utilizado o glyphosate. Como a aplicação de glyphosate ocorre poucos dias antes da semeadura pode-se utilizar em associação como o clorimuronetílico, pois além do efeito sobre as plantas daninhas emergidas, também apresenta ação sobre aquelas que vão emergir (efeito residual) (Bianchi et al., 2010).

Conyza é um gênero de plantas daninhas com o grande adaptabilidade e rusticidade, que pode produzir até 200 mil sementes viáveis por planta, as quais além de serem extremamente leves, facilitando a dispersão, também são capazes de autofecundação, e a junção destes fatores proporciona a dispersão da espécie em diversas regiões (Lorenzi, 2000). Nesse sentido, é uma planta frequentemente encontrada em lavouras perenes, anuais, pastagens, beira de estradas, carreadores e terrenos baldios (Lorenzi, 2008).

O glyphosate é um herbicida não seletivo utilizado há mais de 20 anos no manejo de vegetação, para formar a palhada no sistema de plantio direto. Com a introdução comercial da soja transgênica resistente a glyphosate, o uso desse herbicida aumentou, sendo realizadas de duas a três aplicações por ciclo da cultura. $\mathrm{O}$ uso constante promoveu a seleção de biótipos resistentes a herbicidas (Melo et al., 2004). Vargas \& Roman (2004) relataram que, a partir da safra agrícola de 2004, foi observado controle insatisfatório da espécie Conyza bonariensis com o uso de glyphosate e estudos confirmaram a ocorrência de biótipos resistentes a doses de até seis vezes maiores do que as tradicionalmente utilizadas.

A dessecação é uma das etapas mais importantes para qualquer cultura, pois a aplicação de herbicidas não-seletivos na eliminação da cobertura vegetal assegura a perfeita emergência da cultura, permitindo o crescimento inicial sem interferência de plantas daninhas (Christoffoleti et al., 2007). Para isso, existe a necessidade de uma associação de glyphosate com outro herbicida que apresente efeito residual no solo, pois quando é realizada a associação com herbicidas sem residual podem ocorrer novas infestações.

Portanto, o experimento teve como objetivo, avaliar a eficácia da associação de glyphosate com clorimuron-etílico como dessecação alternativa para o controle de Conyza bonariensis resistente ao glyphosate, em diferentes estádios de desenvolvimento.

$\mathrm{O}$ experimento foi desenvolvido em condições ambientais do Laboratório de Plantas Daninhas (LAPDA), pertencente ao Departamento de Biologia Aplicada à Agropecuária UNESP/FCAV, Jaboticabal-SP.

As sementes (aquênios) de buva (Conyza bonariensis) foram coletadas em área de plantio de citros em diferentes municípios da região e foram colocadas na superfície de um Latossolo Vermelho Escuro, de textura média, acondicionado em vasos plásticos de capacidade volumétrica para $500 \mathrm{~mL}$. Após a semeadura, foi adicionada uma pequena quantidade de areia sobre as sementes para evitar a dispersão das mesmas. Posteriormente, a superfície de cada vaso foi coberta com uma folha de papel pardo, que foi umedecido e assim mantido por 15 dias com irrigação diária, mantendo-se a capacidade de campo próximo a $80 \%$. Anteriormente a esse ensaio, foi realizada uma curva de dose resposta 
onde as mesmas sementes utilizadas nesse trabalho foram resistentes a dose de 2880 g e.a. $\mathrm{ha}^{-1}$ de glyphosate.

O delineamento experimental utilizado foi o inteiramente casualizado, com oito tratamentos seis repetições, sendo estes constituídos pelos estádios de desenvolvimento das plantas de $C$. bonariensis, e caracterizado por plantas com 3 folhas, 4 a 6 folhas, 6 a 9 folhas, 10 a 13 folhas, 13 a 16 folhas, 20 folhas, em florescimento e uma testemunha sem aplicação. Os produtos utilizados e suas respectivas doses foram: Zapp QI $620^{\circledR}$ (glyphosate $1250 \mathrm{~g}$ e.a. ha ${ }^{-1}$ ) a 2,5 L ha ${ }^{-1}$ e Classic $^{\circledR}$ (clorimuron-etílico 15 g i.a. ha ${ }^{-1}$ ) a 60 $\mathrm{g} \mathrm{ha}^{-1}$.

A pulverização dos tratamentos foi realizada em 21 de novembro de 2012, em uma sala de pulverização com o ambiente protegido, onde se utilizou um pulverizador costal pressurizado a $\mathrm{CO}_{2}$, munido de barra com quatro pontas de jato plano ("leque") XR 11002, espaçadas de $0,50 \mathrm{~m}$, regulado com pressão constante de 2 bar, que proporcionou volume de calda correspondente a $200 \mathrm{~L} \mathrm{ha}^{-1}$. No momento aplicação verificou-se temperatura e umidade relativa do ar de $29,7^{\circ} \mathrm{C}$ e $68 \%$, respectivamente.

O controle das plantas daninhas foi avaliado aos 07, 14 e 21 dias após a aplicação (DAA) dos tratamentos, utilizando escala de notas da ALAM (1974), na qual 0\% representou nenhum controle e $100 \%$ controle total da $C$. bonariensis. Aos 21 dias também foi determinada a massa seca da parte aérea das plantas, coletando-as rente ao solo e secas em estufa com circulação forçada de ar a $65^{\circ} \mathrm{C}$, até atingir massa constante. $\mathrm{O}$ efeito sobre a massa seca foi expresso em termos de redução em relação à massa seca da testemunha.

As variáveis avaliadas foram submetidas à análise de variância pelo teste $\mathrm{F}$ e as médias comparadas pelo teste de Tukey a 5\% de probabilidade. Na correlação entre a redução da massa seca em função do estádio de desenvolvimento a equação que melhor ajustouse ao fenômeno foi a de forma sigmoidal de crescimento de Boltzmann:

$$
\mathrm{Y}=\mathrm{A} 2+\frac{(\mathrm{A} 1-\mathrm{A} 2)}{1+\exp ^{(\mathrm{x}-\mathrm{x} 0 \mathrm{0}) d x}}
$$

Na equação, y indica a redução da massa seca, A1 e A2 os valores máximo e mínimo da redução da massa seca, x0 o ponto de inflexão, ou seja, valor da ordenada $x$ que correspondeu ao valor médio da massa seca $(\mathrm{x} 0,(\mathrm{~A} 1+\mathrm{A} 2) / 2)$, e o dx o parâmetro de ajuste, ou seja, o fator de espalhamento da curva, que indica o grau de diminuição da massa seca em função do estádio de desenvolvimento.

Para as plantas de buva que apresentavam estádios de 3 folhas, de 4 a 6 folhas e de 6 a 9 folhas no momento da aplicação, o controle foi de $100 \%, 95 \%$ e $100 \%$ ao final dos 21 DAA, respectivamente (Tabela 1). Resultado semelhante foi observado por Fornarolli et al. (2010) onde o glyphosate $(2,0 \mathrm{~L}$ p.c. $\left.\mathrm{ha}^{-1}\right)+$ clorimuron-etílico $\left(80\right.$ g p.c. ha $\left.^{-1}\right)$ proporcionou controle de $85 \%$ aos 90 DAA, quando aplicado em plantas com 4 a 6 folhas.

Para as plantas de buva com 10 a 13 folhas, o controle se manteve suficiente (61 a $66 \%$ ) até os 21 DAA. Em contrapartida, a aplicação nas plantas com 13 a 16 folhas resultou em controle ineficiente nas duas primeiras avaliações e suficiente $(72 \%)$ aos 21 DAA, caracterizando assim uma evolução.

A aplicação em plantas de buva em estádio mais avançado de desenvolvimento (pré-florescimento) resultou em menor controle, considerado suficiente $(70 \%)$ apenas aos 21 DAA. No florescimento, observou-se que até 21 DAA o controle variou de nenhum a ineficiente. Santos et al., (2010) observaram controle de $75 \%$ aos 80 DAA no tratamento onde foi aplicado glyphosate $\left(2,0\right.$ L p.c. ha $\left.^{-1}\right)+$ clorimuron-etílico (80 g p.c. ha $\left.{ }^{-1}\right)$. 
Tabela 1. Controle de buva (Conyza bonariensis) nos diferentes estádios fenológicos aos 7, 14 e 21 dias após aplicação (DAA). Jaboticabal-SP, 2012.

\begin{tabular}{lccr}
\hline \multirow{2}{*}{ Estádio } & \multicolumn{3}{c}{ Controle (\%) } \\
\cline { 2 - 4 } & 7 DAA & 14 DAA & 21 DAA \\
\hline 3 folhas & $99,66 \mathrm{a}$ & $100,00 \mathrm{a}$ & $100,00 \mathrm{a}$ \\
4 a 6 folhas & $89,66 \mathrm{ab}$ & $90,83 \mathrm{ab}$ & $95,00 \mathrm{a}$ \\
6 a 9 folhas & $86,00 \mathrm{ab}$ & $98,83 \mathrm{a}$ & $100,00 \mathrm{a}$ \\
10 a 13 folhas & $61,66 \mathrm{abc}$ & $64,16 \mathrm{bc}$ & $66,66 \mathrm{ab}$ \\
13 a 16 folhas & $31,66 \mathrm{c}$ & $43,44 \mathrm{c}$ & $72,50 \mathrm{ab}$ \\
20 folhas & $52,50 \mathrm{bc}$ & $50,38 \mathrm{bc}$ & $70,00 \mathrm{ab}$ \\
Florescimento & $30,83 \mathrm{c}$ & $35,00 \mathrm{c}$ & $44,16 \mathrm{~b}$ \\
\hline F & $9,95^{*}$ & $8,14^{*}$ & $4,39^{* *}$ \\
CV (\%) & 33,64 & 34,05 & 31,19 \\
DMS & 39,21 & 42,4 & 44,1 \\
\hline
\end{tabular}

Médias seguidas por mesma letra, na coluna, não diferenciam entre si ao nível de 5\% pelo teste de Tukey; **, * significativo a 1 e $5 \%$ pelo teste $\mathrm{F}$

A porcentagem da redução da massa seca em decorrência da aplicação dos herbicidas foi menor a medida que se aumentou a idade (estádios fenológicos) das plantas de buva, corroborando com os menores níveis de controle constatados visualmente (Figura 1). As maiores reduções no acúmulo de massa seca ocorreram quando os herbicidas foram aplicados nas plantas que apresentavam de 3 a 9 folhas, sendo que nesses estádios o controle foi de $100 \%$.

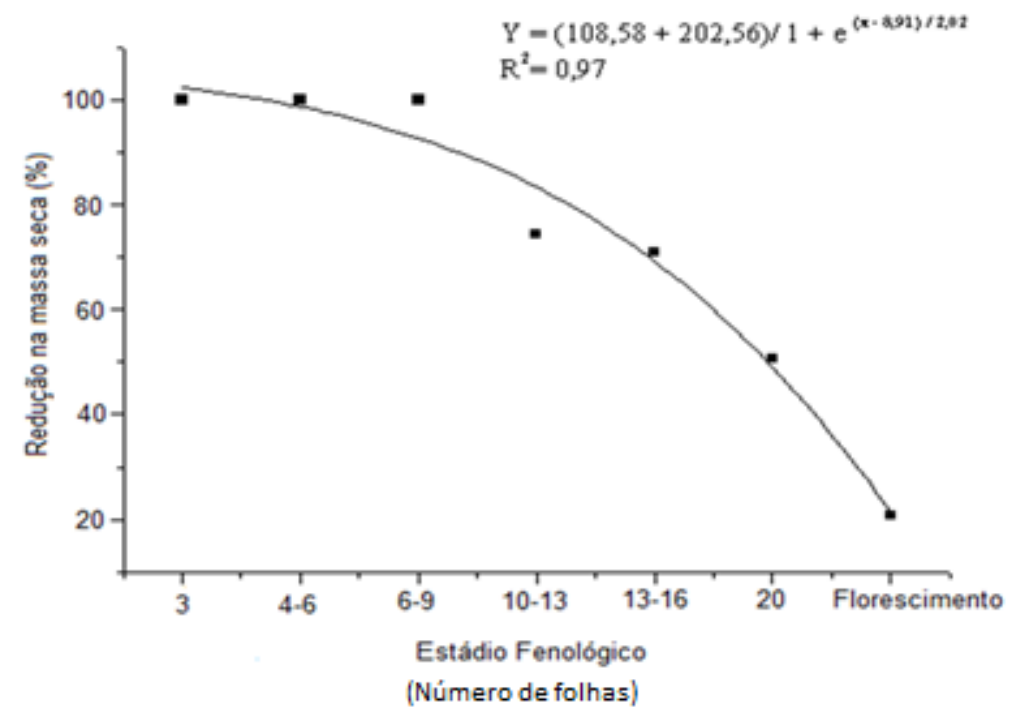

Figura 1. Redução na massa seca de $C$. bonariensis em relação à testemunha (\%) pela aplicação de glyphosate+clorimuron-etílico, em diferentes estádios de desenvolvimento. Jaboticabal-SP, 2012.

Para os demais estádios de crescimento glyphosate+clorimuron-etílico foram inferiores da buva, as porcentagens de controle a $80 \%$, chegando apenas a $20 \%$, quando as proporcionadas pela aplicação de plantas apresentavam pleno florescimento. 
Esses resultados demonstraram a relação entre o estádio da buva no momento da aplicação e a eficácia de controle da mistura de glyphosate+clorimuron-etílico. Além da variabilidade genética inerente aos biótipos de Conyza, outros fatores, como o estádio das plantas e as condições de ambiente, também podem influenciar nos níveis de controle de Conyza spp. (Trezzi et al., 2011).

\section{Conclusões}

O estádio da $C$. bonariensis no momento da aplicação afeta significativamente a eficiência do glyphosate + clorimuron-etílico.

Para se obter níveis excelentes de controle de $C$. bonariensis as aplicações de glyphosate+clorimuron etílico devem ser realizadas em plantas de até 9 folhas.

\section{Referências}

\section{ASOCIACIÓN LATINOAMERICANA DE} MALEZAS - ALAM. Recomendaciones sobre unificación de los sistemas de evaluación en ensayos de control de malezas. ALAM, v.1, n.1, p.35-38, 1974.

BIANCHI, M.A.; ROCKENBACH, D.; SCHNEIDER, T. Seletividade de herbicidas a base de clorimurom-etílico aplicados em pré e em pós-emergência da soja. Seminário Interinstitucional de Ensino, Pesquisa e Extensão, 3, 2010. Cruz Alta-RS. Resumos... Universidade de Cruz Alta, 2010. p.3.

CHRISTOFFOLETI, P.J.; CARVALHO, S.J.P.; NICOLAI, M. Hora certa. Revista Cultivar. 2007. Disponível em: <http://www.cultivar.inf.br> Acesso em: 02 de abril de 2013.

FORNAROLLI, D.A. et al. Efeito de residuais no controle de Conyza spp na região oeste do estado do Paraná. In: XXVII Congresso Brasileiro da Ciência das Plantas Daninhas, 86, 2010. Ribeirão Preto. Resumo... Londrina: Sociedade Brasileira da Ciência das Plantas Daninhas,2010. p.86.
LORENZI, H. Plantas daninhas do Brasil: terrestres, aquáticas, parasitas e tóxicas. Instituto Plantarum, 4 ed. Nova Odessa: Instituto Plantarum, 2008. p.124.

LORENZI, H. Plantas Daninhas do Brasil: terrestres, aquáticas, parasitas e tóxicas. 3 ed., Nova Odessa: Instituto Plantarum, 2000, 143p.

MELO, M.S.C. et al. Avaliação do crescimento dos biótipos de buva $(C$. canadensis e $C$. bonariensis) suscetível e resistente ao glifosato. 2004. 48f. Trabalho de conclusão de Curso em Agronomia, Universidade de São Paulo.

SANTOS, B.C. et al. Uso de Herbicidas no controle de Conyza bonariensis resistente ao glifosato. XXVII Congresso Brasileiro da Ciência das Plantas Daninhas, 43, 2010. Ribeirão Preto. Resumo... Londrina: Sociedade Brasileira da Ciência das Plantas Daninhas, 2010. p.86.

TREZZI, M.M. et al. Resistência ao glyphosate em biótipos de buva (Conyza spp.) das regiões oeste e sudoeste do Paraná. Planta Daninha, v.29, n.5, p.1113-1120, 2011.

VARGAS, L.; ROMAN, E.S. Manual de manejo e controle de plantas daninhas. 1.ed., Bento Gonçalves - RS: Embrapa Uva e Vinho, 2004, 652p. 